\title{
Detection of Race-Specific Resistance Against Puccinia coronata f. sp. avenae in Brachypodium Species
}

\author{
Vahid Omidvar, Sheshanka Dugyala, Feng Li, Susan M. Rottschaefer, Marisa E. Miller, Mick Ayliffe, \\ Matthew J. Moscou, Shahryar F. Kianian, and Melania Figueroa ${ }^{\dagger}$
}

First, second, third, fourth, fifth, eighth, and ninth authors: Plant Pathology, University of Minnesota, St. Paul; sixth author: CSIRO Agriculture and Food, ACT, Australia; seventh author: The Sainsbury Laboratory, Norwich Research Park, Norwich NR4 7UH, U.K.; eighth author: Cereal Disease Laboratory, United States Department of Agriculture-Agricultural Research Service, St. Paul, MN, USA; and ninth author: Stakman-Borlaug Center for Sustainable Plant Health, University of Minnesota, St. Paul.

Accepted for publication 14 June 2018.

\begin{abstract}
Oat crown rust caused by Puccinia coronata f. sp. avenae is the most destructive foliar disease of cultivated oat. Characterization of genetic factors controlling resistance responses to Puccinia coronata f. sp. avenae in nonhost species could provide new resources for developing disease protection strategies in oat. We examined symptom development and fungal colonization levels of a collection of Brachypodium distachyon and B. hybridum accessions infected with three North American P. coronata f. sp. avenae isolates. Our results demonstrated that colonization phenotypes are dependent

on both host and pathogen genotypes, indicating a role for race-specific responses in these interactions. These responses were independent of the accumulation of reactive oxygen species. Expression analysis of several defense-related genes suggested that salicylic acid and ethylene-mediated signaling but not jasmonic acid are components of resistance reaction to $P$. coronata $\mathrm{f}$. sp. avenae. Our findings provide the basis to conduct a genetic inheritance study to examine whether effector-triggered immunity contributes to nonhost resistance to $P$. coronata f. sp. avenae in Brachypodium spp.
\end{abstract}

Oat crown rust caused by the obligate biotrophic rust fungus Puccinia coronata f. sp. avenae is the most widespread and damaging foliar disease of cultivated oat (Avena sativa L.) (Nazareno et al. 2018). Symptoms of crown rust infection manifest in the foliar tissue, causing a reduction in photosynthetic capacity and, thus, affecting grain size and quality (Holland and Munkvold 2001; Simons 1985). The most sustainable method to control this devastating disease is the use of genetic resistance (Carson 2011). Novel sources of genetic resistance may therefore translate into novel crop protection strategies.

In general, plant disease resistance to would-be pathogens can be conferred by either constitutive or induced barriers (Heath 2000; Nürnberger and Lipka 2005). Physical barriers such as rigid cell walls and waxy cuticles as well as preformed antimicrobial compounds are some of the constitutive obstacles that explain why plants are immune to most microbes. Nevertheless, certain microbes have evolved strategies to overcome these barriers and, in such instances, plant-microbe incompatibility is based upon pathogen recognition and the induction of plant defense responses (Heath 2000; Periyannan et al. 2017).

Inducible defense responses in plants are mediated by a tightly regulated two-tier immune recognition system that, depending on the physiological characteristics of the potential pathogen, may or may not be effective at preventing microbial colonization (Dodds

${ }^{\dagger}$ Corresponding author: Melania Figueroa; E-mail: figue031@umn.edu

Funding: We acknowledge support by the University of Minnesota Experimental Station USDA-NIFA Hatch/Figueroa project MIN-22-058, as well as the USDAARS The University of Minnesota Standard Cooperative Agreement (3002-1103100053115 ) between S. F. Kianian and M. Figueroa. M. J. Moscou is supported by the Gatsby Foundation and Biotechnology and Biological Sciences Research Council (BB/P012574/1).

*The $\boldsymbol{e}$-Xtra logo stands for "electronic extra" and indicates that one supplementary table and five supplementary figures are published online.

(C) 2018 The American Phytopathological Society and Rathjen 2010). The first layer of microbial recognition is controlled by cell surface-associated receptors, named pattern recognition receptors (PRRs). PRRs recognize conserved and essential microbial molecules known as pathogen-associated molecular patterns (PAMPs) or plant-derived damage-associated molecular patterns (DAMPs). This recognition leads to the activation of a range of broad-spectrum basal defenses that constitute PAMP-triggered immunity (PTI) (Zipfel 2008). PAMP in pathogenic fungi such as the crown rust pathogen include chitin or xylanases, which are essential constituents of the fungal cell wall. In contrast, DAMP are not necessarily pathogen derived and include plant cell wall fragments and plant peptides released during infection.

Adapted pathogens manipulate PTI signaling events and suppress basal defenses by secreting a suite of effector proteins into plant cells, thereby enabling successful plant colonization in some instances (Toruño et al. 2016). However, disease resistance against adapted pathogens can still occur if the plant can recognize one or more of these secreted effector molecules. Effector recognition generally occurs by plant intracellular nucleotide-binding leucine rich repeat (NB-LRR) receptors that each induce defense responses upon recognition of a cognate pathogen effector, also known as an avirulence (Avr) protein. This second layer of pathogen recognition, referred to as effector-triggered immunity (ETI), frequently results in a localized hypersensitive cell death response (HR) at attempted infection sites and is the underlying molecular basis of the genefor-gene concept (Dodds and Rathjen 2010; Ellis et al. 2014; Flor 1971). ETI is highly specific, with resistance only occurring if the adapted pathogen isolate expresses an effector that is recognized by a corresponding NB-LRR in the infected plant.

The delivery of rust effector proteins into host plants is mediated by distinct fungal infection structures called haustoria (Catanzariti et al. 2006; Garnica et al. 2014; Panstruga and Dodds 2009). Only a small number of effectors have been characterized in rust fungi (Chen et al. 2017; Maia et al. 2017; Ravensdale et al. 2011; Salcedo et al. 2017); however, genome-wide effector mining suggests that rust pathogens may deploy hundreds of effector molecules via the 
haustorium during infection (Cantu et al. 2013; Duplessis et al. 2011; Hacquard et al. 2012; Nemri et al. 2014; Rutter et al. 2017). Oat crown rust populations are typified by a complex race structure, which likely originates from variation in the array of effectors present in different pathogen genotypes (Carson 2011; Chong et al. 2000; Nazareno et al. 2018). For years, oat breeding programs have relied upon naturally occurring resistance in Avena spp., most likely mediated by $N B-L R R$ genes, to protect against crown rust. However, the resistance of these oat varieties is often rapidly overcome by evolution of the crown rust pathogen to avoid host plant recognition. Therefore, achieving increased durability in oat crown rust resistance requires new sources of genetic immunity to be identified and further advances made in our understanding of the molecular basis of rust recognition in host and nonhost plant species.

Nonhost plant species potentially offer an untapped resistance resource. Nonhost resistance (NHR) is typically described in the context of a dichotomy that distinguishes it from host resistance. NHR is defined as genotype-independent and effective against all genetic variants of a nonadapted pathogen species, whereas host resistance is genotype-dependent and effective only against a subset of genetic variants of an adapted pathogen (Mysore and Ryu 2004). This paradigm has been gradually changing as accumulating evidence suggests that signaling pathways and defense mechanisms overlap in nonhost and host resistance and that microbial adaptation to plant species does not conform to a simple qualitative distinction (Bettgenhaeuser et al. 2014; Dawson et al. 2015; Figueroa et al. 2015; Gill et al. 2015; Thordal-Christensen 2003). Instead, disease phenotypes observed for different plant-pathogen interactions span a continuous spectrum of outcomes ranging from immunity to susceptibility, with many intermediate interactions, making the classification of nonhost versus host systems problematic (Bettgenhaeuser et al. 2014; Dawson et al. 2015). Regardless of the terminology, identifying the molecular determinants of nonhost or intermediate resistance is of great interest because this type of resistance could be durable and broad spectrum and contribute significantly to crop improvement.

Brachypodium distachyon, a small grass closely related to cereals, is considered a nonhost to several rust fungi species related to $P$. coronata f. sp. avenae, such as $P$. emaculata, $P$. striiformis, P. graminis, and P. triticina (Ayliffe et al. 2013; Barbieri et al. 2011; Bettgenhaeuser et al. 2014; Bossolini et al. 2007; Dawson et al. 2015; Figueroa et al. 2013, 2015; Gill et al. 2015). Variation in fungal colonization in some of these interactions suggests that it may be possible to genetically dissect these types of immune responses and harness them for engineering rust disease resistance (Figueroa et al. 2015). In this study, we examined the interaction between $P$. coronata $\mathrm{f}$. sp. avenae and $B$. distachyon, as well as $B$. hybridum. B. hybridum is an allotetraploid species originated from the hybridization of the diploid species $B$. distachyon and B. stacei (López-Alvarez et al. 2012).

Pathogen susceptibility in plants, particularly to rust fungi, is a process, that remains poorly characterized. Our study shows that $P$. coronata f. sp. avenae can infect $B$. distachyon and $B$. hybridum leaves and grow extensively but cannot sporulate. These findings open the possibility of investigating mechanisms that confer partial rust susceptibility in Brachypodium spp. Gene expression analysis of an ortholog of the putative rust susceptibility factor in wheat, which encodes a hexose transporter (Moore et al. 2015), suggested that sugar transport may also be important to sustain the growth of $P$. coronata $\mathrm{f}$. sp. avenae in $B$. distachyon. In addition to this, we found evidence for race-specific resistance in both species, supporting the model proposed by Schulze-Lefert and Panstruga (2011), which postulates a role of ETI in NHR due to the phylogenetic relatedness between the nonhost and host species. These findings provide a framework to conduct genetic inheritance studies to dissect recognition of $P$. coronata $\mathrm{f}$. $\mathrm{sp}$. avenae by $B$. distachyon and $B$. hybridum and identify loci governing intermediate oat crown rust susceptibility.

\section{MATERIALS AND METHODS}

Plant and fungal materials. In all, 22 accessions of $B$. distachyon (ABR6, ABR7, Adi12, Adi13, Adi15, Bd1-1, Bd18-1, Bd21, Bd21-3, Bd2-3, Bd29-1, Bd30-1, Bd3-1, BdTR10H, BdTR13K, Foz1, J6.2, Jer1, Koz5, Luc1, Mon3, and Tek4) and 3 accessions of B. hybridum (Bou1, Bel1, and Pob1) were used in this study. Seed were obtained from the John Innes Centre (Dawson et al. 2015), Aberystwyth University (Mur et al. 2011), Joint Genome Institute and Montana State University (Vogel et al. 2009), Universidad Politécnica de Madrid (Dr. Elena Benavente), and United States Department of Agriculture-Agricultural Research Service (USDA-ARS) Plant Science Unit, St. Paul, MN, USA (Garvin et al. 2008). All plants were increased by single-seed descent prior to conducting this study. The cultivated oat (A. sativa) variety Marvelous was used as a susceptible host to $P$. coronata $\mathrm{f}$. sp. avenae. This study used three North American oat crown rust isolates-12NC29 (race LBBB) and 12SD80 (race STTG) (Miller et al. 2018), collected in 2012, and a historic race, 203 (race QBQT) — known to be avirulent to the oat variety Victoria (Chang and Sadanaga 1964). Isolates were obtained from the rust collection available at the USDA-ARS Cereal Disease Laboratory, St. Paul, MN, USA, and physiological race analysis was conducted following a standard nomenclature system using a set of oat differentials (Chong et al. 2000; Nazareno et al. 2018). Reported race assignment conveys consistent results from three independent experiments. Virulence phenotypes of $P$. coronata f. sp. avenae isolates on oat differentials with infection types 0,$0 ;, ;$, ; $\mathrm{C}, 1 ;, 1,2,3,3+$, and 4 were converted to a 0 -to- 9 numeric scale, respectively, for heat map generation.

Inoculation and pathogen assays. Brachypodium and oat seedlings were grown with cycles of $18 \mathrm{~h}$ of light and $6 \mathrm{~h}$ of darkness at 24 and $18^{\circ} \mathrm{C}$ (day and night, respectively) and 50\% humidity. Urediniospores were activated by heat shock treatment at $45^{\circ} \mathrm{C}$ for $15 \mathrm{~min}$ to break cold-induced dormancy and suspended in an oil carrier (Isopar M; ExxonMobil) for spray inoculation. Seedlings of Brachypodium accessions and oat were inoculated using $50 \mu \mathrm{l}$ of each $P$. coronata $\mathrm{f}$. sp. avenae inoculum (urediniospores at $10 \mathrm{mg} / \mathrm{ml}$ ) at three-leaf and first-leaf stages, respectively. For mock inoculation, seedlings were sprayed with oil without urediniospores. Infected seedlings were placed in dew chambers in the dark for $12 \mathrm{~h}$ with intermittent misting for 2 min every $30 \mathrm{~min}$. After $12 \mathrm{~h}$, misting was stopped and seedlings were exposed to light for $2 \mathrm{~h}$ before they were placed back in growth chambers. Infected primary leaves of oat and secondary leaves of Brachypodium accessions were collected for analysis. Presence (+) or absence (-) of macroscopic symptoms, including chlorosis or necrosis as well as severity of the symptoms (shown as increments of + ), were evaluated at 14 days postinfection (dpi) in two independent experiments (biological replicates). Each biological replicate simultaneously tested all accessions, and five plants were examined per accession. Each plant was considered a technical replicate within one independent experiment. Digital images were captured using a stereomicroscope (Olympus model SZX16). To examine correlations between necrosis or chlorosis and estimates of fungal colonization (mean values), symptoms described as,,,-++++++ , and ++++ were transformed to numerical values 0 to 4 , respectively, to calculate a Spearman's rank correlation coefficient.

Analysis of fungal colonization by microscopy. Both infected secondary Brachypodium leaves at 14 dpi and infected primary A. sativa (variety Marvelous) leaves at 12 dpi were cut into 1-cm-long sections and stained with wheat germ agglutinin Alexa Fluor 488 conjugate (WGA-FITC; ThermoFisher Scientific) to visualize fungal colonies, as previously described (Ayliffe et al. 2013; Dawson et al. 2015). Visualization of fungal intracellular growth was carried out using a fluorescence microscope (Leica model DMLB) under blue light with a 450- to 490-nM excitation filter. The percentage of leaf colonized (pCOL) by $P$. coronata f. sp. avenae was estimated according to the method of Dawson et al. 
(2015), with a modification to report $0,0.5,0.75$, and 1 scores for disjointed fields of view with hyphal growth less than 15 , between 15 and 50,50 to 75 , and greater than $75 \%$, respectively. Two independent experiments (biological replicates) were evaluated per $P$. coronata f. sp. avenae isolate (12SD80, 203, and 12NC29) and each biological replicate included three leaves. Each leaf was considered a technical replicate within one independent experiment. pCOL values from all three leaves were combined to obtain a mean and standard error of the mean. Fungal development was also examined in whole-mounted infected leaves of B. distachyon accessions ABR6 and Bd21 and oat at 1, 2, 3, and 6 dpi. The percentage of urediniospores that successfully germinated and formation of various infection structures, including appressorium (AP), substomatal vesicle (SV), haustorium-mother cell (HMC), and established colonies (EC), were recorded in WGA-FITCstained samples. Three independent experiments (biological replicates) were conducted and simultaneously evaluated for infections with $P$. coronata f. sp. avenae isolates 12SD80, 203, and 12NC29. Each biological replicate recorded fungal development for 100 infection sites. Mean and standard error of the mean per infection structure category were calculated based on all three biological replicates.

Analysis of $\mathrm{H}_{2} \mathrm{O}_{2}$ accumulation. $\mathrm{H}_{2} \mathrm{O}_{2}$ accumulation was evaluated using 3,3'-diaminobenzidine (DAB) staining, as described by Thordal-Christensen et al. (1997). Infected leaves were stained in DAB aqueous solution at $1 \mathrm{mg} / \mathrm{ml}$ and $\mathrm{pH} 3.8$ for $4 \mathrm{~h}$ in darkness and destained in Farmer's fixative for $12 \mathrm{~h}$. Three independent experiments (biological replicates) were conducted. Each biological replicate included one to two infected secondary leaves to record the number of urediniospores from 100 samples within a 500- $\mu \mathrm{m}$ distance of a DAB staining site at 2, 4, and 6 dpi. The oat differential that contains the resistance gene Pc91, which confers resistance to rust isolates $12 \mathrm{SD} 80$ and $12 \mathrm{NC} 29$, was included as a positive experimental control for detection of $\mathrm{H}_{2} \mathrm{O}_{2}$. Three negative controls were used, including an oat differential that contains the resistance gene $P c 14$, which is not effective against 12 SD80 and 12NC29; oat variety Marvelous infected with 12SD80 and 12NC29; and mock-inoculated Marvelous. Samples were examined using an upright light microscope (Nikon Eclipse 90i). Mean and standard error of the mean of the number of urediniospores associated with $\mathrm{H}_{2} \mathrm{O}_{2}$ accumulation were calculated based on all three biological replicates. Digital micrographs were captured with a Nikon D2-Fi2 color camera using brightfield and objective lenses $(\times 4$ and $\times 10$ ). Multiple images were acquired in $\mathrm{X}, \mathrm{Y}$, and $\mathrm{Z}$ planes using a Z-series process using the Nikon Elements software. Z-stacking images were treated with an extended depth of focus function to focus all the planes.

Quantitative polymerase chain reaction quantification of fungal DNA. Genomic DNA was extracted from infected and mock-treated secondary leaves of $B$. distachyon accessions ABR6 and $\mathrm{Bd} 21$ at 3, 7, and 12 dpi using the DNeasy Plant Mini Kit (Qiagen). The relative abundance of fungal DNA was measured using the Femto Fungal DNA Quantification Kit (Zymo Research) based on quantification of internal transcribed spacer (ITS) regions using ITS-specific primers and fungal DNA standards provided by the manufacturer. Polymerase chain reaction (PCR) was conducted using a CFX96 Real-Time system (Bio-Rad) and thermal cycles were set for initial denaturation at $95^{\circ} \mathrm{C}$ for $10 \mathrm{~min} ; 45$ cycles of $95^{\circ} \mathrm{C}$ for $30 \mathrm{~s}, 50^{\circ} \mathrm{C}$ for $30 \mathrm{~s}$, and $60^{\circ} \mathrm{C}$ for $60 \mathrm{~s}$; followed by a final extension cycle at $72^{\circ} \mathrm{C}$ for $7 \mathrm{~min}$. The Brachypodium GAPDH gene was also quantified in the same DNA samples using gene-specific primers (Hong et al. 2008). Fungal DNA level was normalized relative to the plant $G A P D H$ value in each sample. Four independent experiments (biological replicates) were analyzed per time point per isolate, with two technical replicates within each biological replicate. Mean and standard error of the mean per condition (fungal isolate by Brachypodium accession by time point) were calculated based on data from all four experiments. Correlation between accumulation of fungal DNA, combined for all isolates at each time point ( 3,7 , and $12 \mathrm{dpi})$, and estimates of fungal colonization, combined for all isolates at $14 \mathrm{dpi}$, was determined using a Pearson's correlation coefficient test.

RNA extraction and reverse-transcription quantitative PCR analysis. Total RNA was extracted from infected and mocktreated secondary leaves of $B$. distachyon accessions ABR6 and $\mathrm{Bd} 21$ at 12, 24, 48, and $72 \mathrm{~h}$ postinfection (hpi) using the RNeasy Plant Mini Kit (Qiagen). For reverse-transcription quantitative PCR (RT-qPCR), cDNA was synthesized using the PrimeScript First-Strand cDNA Synthesis Kit (Takara) and amplification was performed using the SensiFAST SYBR Lo-ROX Kit (Bioline). Sequences of gene-specific primers reported by Gill et al. (2015) and Mandadi and Scholthof (2012) and those used in our study are listed in Supplementary Table S1. The GAPDH, Ubi4, and Ubil8 genes were examined as potential reference genes (Hong et al. 2008). Expression levels were normalized using the plant GAPDH gene after comparing PCR efficiencies and variation of quantification cycle $(\mathrm{Cq})$ values for all three genes across time points in mock- or pathogen-inoculated Brachypodium accessions (ABR6 and $\mathrm{Bd} 21$ ). PCR thermal cycles were set for initial denaturation at $95^{\circ} \mathrm{C}$ for $2 \mathrm{~min}, 40$ cycles of $95^{\circ} \mathrm{C}$ for $5 \mathrm{~s}$, followed by annealing or extension at $60^{\circ} \mathrm{C}$ for $20 \mathrm{~s}$ in a CFX96 Real-Time PCR system (Bio$\mathrm{Rad})$. Data were collected from three independent experiments (biological replicates) and each biological replicate included two technical replicates. Differential expression (DE) values were calculated as normalized fold changes of the expression using the $\Delta \Delta C T$ method (Livak and Schmittgen 2001), and DE value $\geq 2$ was considered to be a significant change in gene expression.

\section{RESULTS}

Variation in resistance response of Brachypodium accessions to $P$. coronata $\mathbf{f}$. sp. avenae infection. To examine the ability of $P$. coronata $\mathrm{f}$. sp. avenae to infect nonhost species $B$. distachyon and B. hybridum, we evaluated the disease responses of 25 different Brachypodium accessions to three North American P. coronata f. sp. avenae isolates (12SD80, 203, and 12NC29). First, we characterized the virulence phenotypes of these isolates using a set of oat differentials (Fig. 1A). All three isolates are fully virulent on the susceptible oat variety Marvelous, with obvious sporulation occurring at $14 \mathrm{dpi}$ (Fig. 1B and C). In contrast, no pustules were observed on any Brachypodium accession 30 dpi, which suggests that the asexual phase of the $P$. coronata $\mathrm{f}$. sp. avenae life cycle cannot be completed on either B. distachyon or B. hybridum. However, macroscopic symptoms were observed on Brachypodium accessions in response to challenge with these rust isolates (Fig. 1D and E; Table 1), with some accessions developing chlorosis or necrosis of varying severity (Fig. 1F; Table 1 ). These symptoms were dependent upon both the accession genotype and rust genotype. For example, the necrosis severity of accession Bd1-1 was high in response to isolate $12 \mathrm{SD} 80$ but low upon infection with isolates 203 and $12 \mathrm{NC} 29$, whereas chlorosis severity in accession Adi13 was higher when challenged with isolates 12SD80 and 12NC29 but lower in response to isolate 203. Some Brachypodium accessions such as $\mathrm{Bd} 2-3, \mathrm{Bd} 3-1$, and Tek4 reacted differently to all three rust isolates, with different necrosis and chlorosis severities observed in each interaction. ABR6 consistently showed minimal symptom development, whereas accessions such as $\mathrm{Bd} 21, \mathrm{Bd} 21-3$, and Koz 5 displayed more extreme necrosis and chlorosis responses to all three isolates.

In parallel, all accessions were analyzed microscopically to determine the extent of $P$. coronata f. sp. avenae infection for each isolate. For all three isolates, urediniospores germinated to produce appressoria and penetrated the plant, indicating that Brachypodium accessions are recognized as a potential host by $P$. coronata f. sp. avenae (Supplementary Fig. S1). A large variation in rust growth was observed among these Brachypodium accessions (Fig. 2A), 
although growth was always less than that observed on the oat host. Microscopically, no P. coronata f. sp. avenae isolate showed initiation of uredinia on any Brachypodium accession, confirming the nonhost status of $B$. distachyon and $B$. hybridum to this phytopathogen.

In general, $P$. coronata $\mathrm{f}$. sp. avenae isolates 12 SD80 and 203, which are more broadly virulent on the oat differentials ( 27 and 12 , respectively) than isolate $12 \mathrm{NC} 29$ (5), showed more extensive growth on all tested Brachypodium accessions (Fig. 2A). Maximum colonization was greatest for isolate $12 \mathrm{SD} 80$, which colonized approximately $79 \%$ of the leaf area of accession $\mathrm{Bd} 21-3$, while isolate 203 colonized approximately $64 \%$ of the leaf area of accession Adi15. In contrast, the maximum colonization for isolate
12NC29 was approximately $41 \%$ of the leaf area of accession Koz5. For all three isolates, Koz5 and Bd21-3 were among those $B$. distachyon accessions with the greatest fungal growth, whereas B. distachyon accessions ABR6 and Foz1, as well as B. hybridum accession Pob1, had the least fungal growth.

The fungal growth of each isolate and accession combination was scored relative to the most fungal growth observed for each isolate (Supplementary Fig. S2). Interestingly, some accessions (i.e., Bd30-1, Bd3-1, and BdTR10H) were substantially infected by isolates 12 SD80 and 203 whereas growth of $12 \mathrm{NC} 29$ was more restricted. In contrast, accession Tek4 was similarly infected by isolates 12 SD 80 and $12 \mathrm{NC} 29$ but had greater growth of 203, while isolate 12SD80 grew more prolifically on accession Mon3 than
A

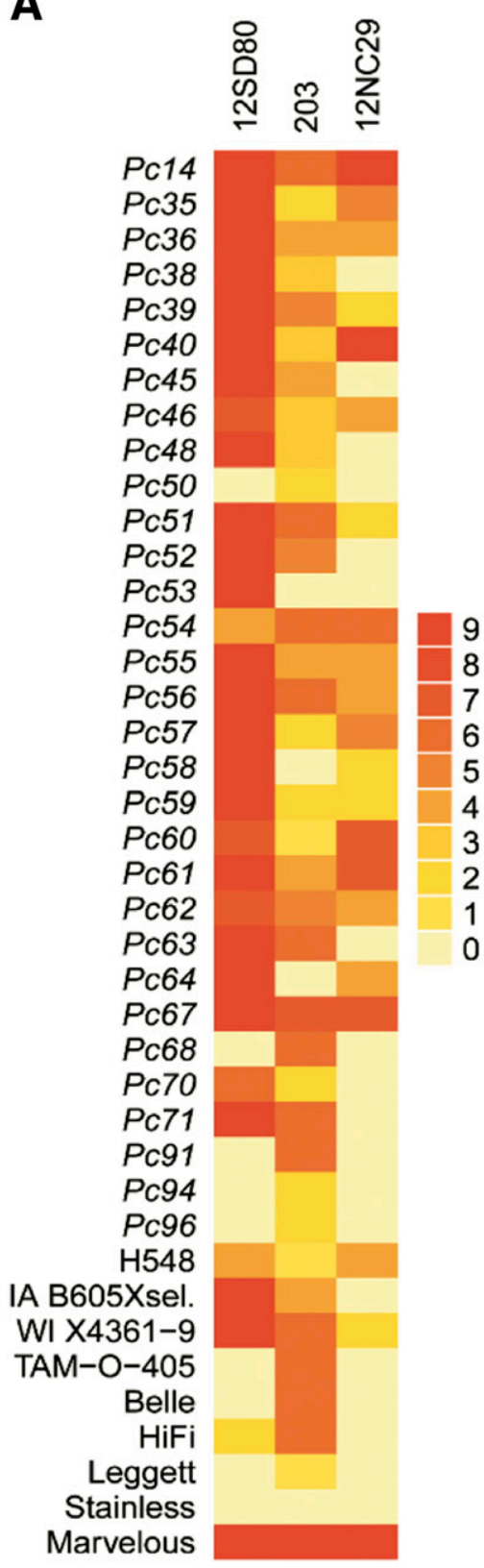

B

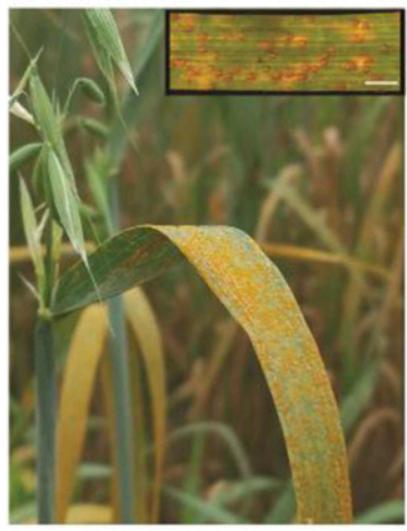

C
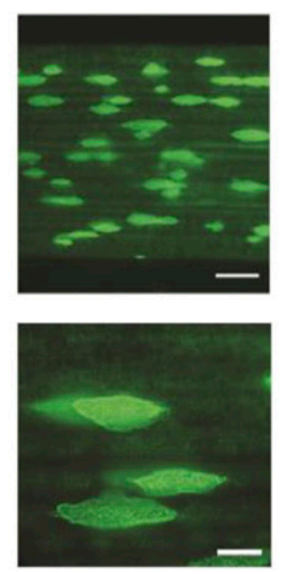

$\mathbf{F}$
D ABR6
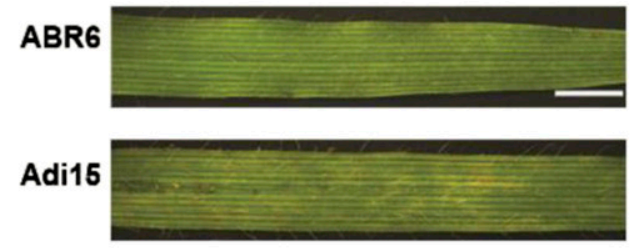

Bd21-3

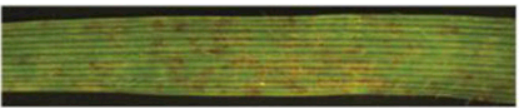

Bd21

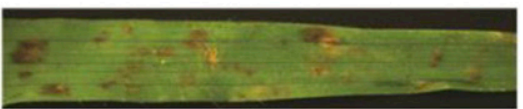

E
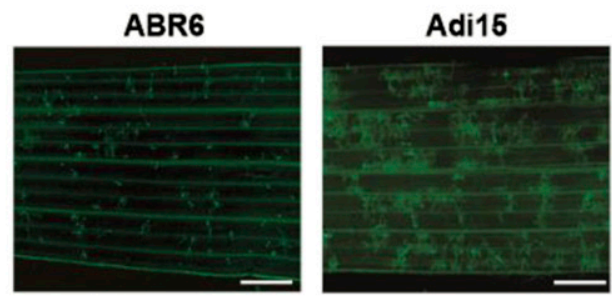

Bd21-3
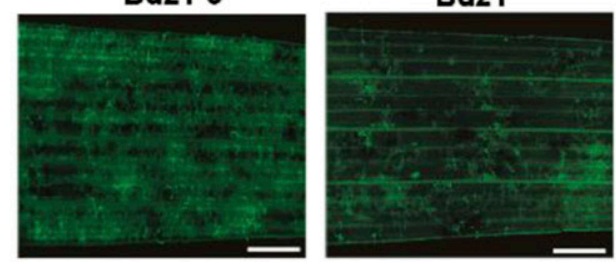

Chlorosis

Necrosis

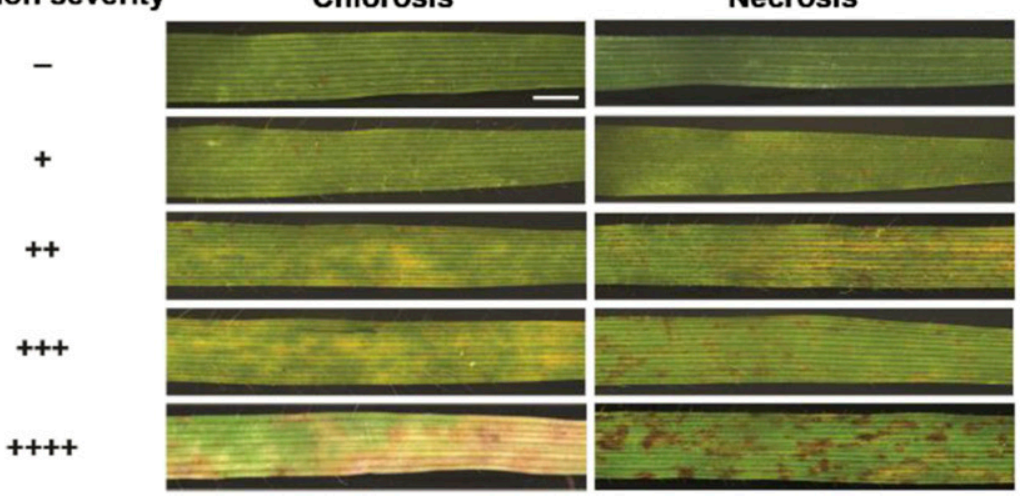

Fig. 1. Infection of oat and Brachypodium accessions with Puccinia coronata f. sp. avenae. A, Heat map of virulence phenotypes of $P$. coronata f. sp. avenae isolates on oat differentials. B and C, Formation of pustules and sporulation on infected susceptible oat leaves (Marvelous), respectively. D and E, Variation of infection symptoms and fungal colonization, respectively, on four Brachypodium accessions. F, Absence (-) or presence (+) of chlorosis or necrosis in Brachypodium accessions inoculated with $P$. coronata f. sp. avenae at 14 days postinfection. Level of symptom severity is indicated by the number of "+" characters. Symptoms correspond to the representative isolate 12SD80, except for the absence of necrosis which corresponds to isolate 203. Scale bars indicate $2 \mathrm{~mm}$ (B, D, and F), $0.5 \mathrm{~mm}(\mathrm{C}$, top), $0.25 \mathrm{~mm}(\mathrm{C}$, bottom), and $0.5 \mathrm{~mm}(\mathrm{E})$. 
did either isolates 203 and 12NC29. Remarkably, we did not observe a correlation between the degree of necrosis and fungal colonization levels for each isolate $(\rho=0.39-0.44, P=0.03$ to 0.05 , Spearman's test). Weak correlations were found between chlorosis and colonization levels of 12 SD80 ( $\rho=0.62, P=1.37 \mathrm{e}-06)$ and 203 ( $\rho=$ $0.53, P=0.0064)$ in contrast to $12 \mathrm{NC} 29(\rho=0.30, P=0.15)$. For example, Bd29-1 showed extensive necrosis and chlorosis when inoculated with isolate 12SD80 in contrast to 203 but had high levels of colonization by both isolates. Accession Bd18-1 developed the highest necrosis and chlorosis in response to $12 \mathrm{NC} 29$ but supported the lowest growth of this isolate. In contrast, the most obvious symptoms on Jer1 correlated with the greatest fungal growth, in this case by isolate $12 \mathrm{SD} 80$.

The variation in fungal growth occurring on different Brachypodium accessions suggests that it may be possible to dissect the genetic architecture controlling this NHR against $P$. coronata f. sp. avenae. Given the availability of an ABR6 $\times \mathrm{Bd} 21 \mathrm{~F}_{4: 5}$ $B$. distachyon family (Bettgenhaeuser et al. 2017) and the differences observed in $P$. coronata f. sp. avenae infection patterns (Fig. 2A), these two parental accessions were further analyzed. To further confirm the colonization values estimated for ABR6 and Bd21, fungal DNA accumulation was quantified by qPCR for each rust isolate over a time course experiment of 3, 7, and 12 dpi (Fig. 2B). Fungal DNA levels of each isolate increased in both accessions; however, statistically significant differences in the accumulation of DNA were observed between accessions at 7 and 12 dpi. Fungal DNA abundance was higher in accession $\mathrm{Bd} 21$ for all three isolates compared with ABR6, while isolate $12 \mathrm{NC} 29$ had the least growth on both accessions. A strong correlation was observed between levels of fungal colonization of all three isolates in ABR6 and Bd21 and their fungal DNA abundance at $7 \mathrm{dpi}(r=0.93, P=0.0056$, Pearson's test) and 12 dpi $(r=0.91, P=0.0098)$, whereas the correlation was not significant at $3 \mathrm{dpi}(r=0.76, P=0.07)$. These results validate fungal colonization estimates shown in Figure 2A.

Development of infection structures of $P$. coronata $f$. sp. avenae isolates on $B$. distachyon ABR6 and Bd21. The development of infection structures (Fig. 3A) of isolates 12SD80, 203 , and $12 \mathrm{NC} 29$ in a time course experiment $(1,2,3$, and $6 \mathrm{dpi})$ was compared between ABR6 and Bd21, with the susceptible oat variety Marvelous included as a positive control. Spore germination rates and AP development of all three rust isolates were similar on ABR6, Bd21, and oat (Fig. 3B). However, fungal growth on both Brachypodium accessions was significantly slower than on susceptible oat, with fewer SV, HMC, and EC produced at 1, 2, and 3 dpi. The infection progression was generally slower on accession ABR6 than Bd21, while isolate 12SD80 grew at a faster rate on $B$. distachyon compared with the other two isolates, as demonstrated by the increased percentage of infection sites that formed SV in both accessions at $1 \mathrm{dpi}$. The most noticeable differences in the parental accessions ABR6 and Bd21 were related to the development of SV at 2 dpi with isolate 12SD80 and HMC at 3 dpi for isolates 12 SD80 and 203.

Histological analysis of reactive oxygen species in B. distachyon ABR6 and Bd21. The accumulation of $\mathrm{H}_{2} \mathrm{O}_{2}$ in mesophyll cells was examined by DAB staining in accessions ABR6 and $\mathrm{Bd} 21$ upon infection with isolates 12SD80, 203, and 12NC29 at 2, 4, and 6 dpi (Table 2; Supplementary Fig. S3). We conducted three independent experiments examining, in each case, 100 urediniospores from all three rust isolates. For isolate 12SD80, we found only a small number of urediniospores within a $500-\mu \mathrm{m}$ distance from DAB sites in ABR6 and Bd21, with slightly higher numbers of DAB sites in ABR6 than in Bd21 at 2 and 4 dpi (Table 2). In contrast, DAB accumulation was rare in response to isolates 203 and $12 \mathrm{NC} 29$. We used an oat line carrying the $P c 91$ gene, which confers resistance against 12 SD80 and $12 \mathrm{NC} 29$ isolates (Fig. 1A), as a positive experimental control. In this case, we observed a significantly greater proportion of urediniospores (approximately 50 to 60\%) from 12SD80 and $12 \mathrm{NC} 29$ in association with $\mathrm{H}_{2} \mathrm{O}_{2}$ accumulation sites. The staining intensity and size of the $\mathrm{H}_{2} \mathrm{O}_{2}$ accumulation sites were also greater in the positive control samples than those in ABR6 and $\mathrm{Bd} 21$. The resistance gene $P c 14$, which is not effective against 12SD80 and $12 \mathrm{NC} 29$ isolates; susceptible oat Marvelous infected with 12SD80 and 12NC29 (Fig. 1A); and mock inoculated Marvelous were used as negative controls and did not result in accumulation of $\mathrm{H}_{2} \mathrm{O}_{2}$ (Table 2). These data suggest that $\mathrm{H}_{2} \mathrm{O}_{2}$ accumulation is not a common feature of $B$. distachyon NHR to $P$. coronata f. sp. avenae.

TABLE 1. Variation of symptoms in Brachypodium accessions infected with Puccinia coronata f. sp. avenae isolates ${ }^{\mathrm{a}}$

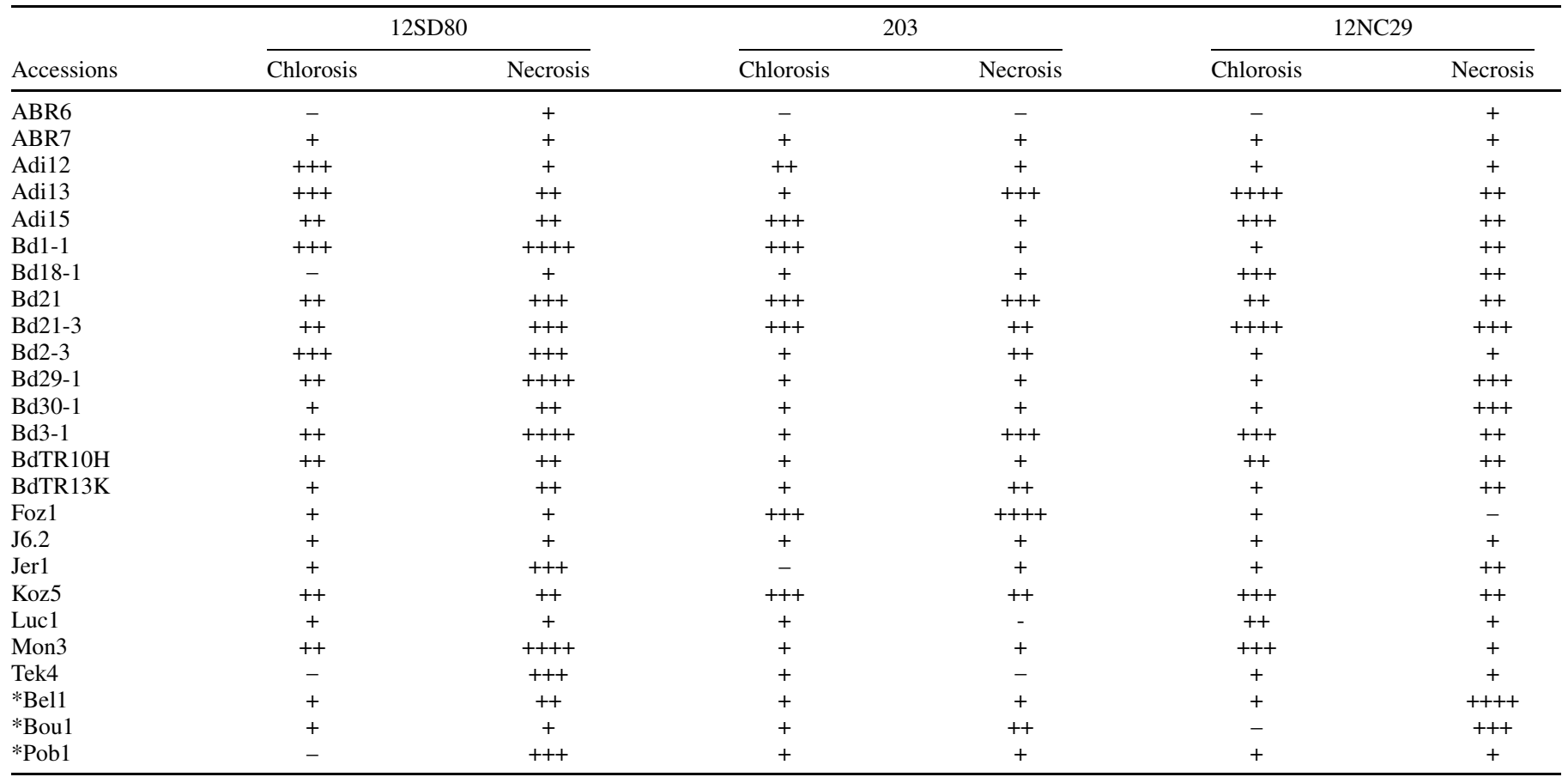

a Accessions marked with asterisks correspond to Brachypodium hybridum and those without an asterisk are B. distachyon. Symbols + and - show presence or absence, respectively, of macroscopic symptoms, and the number of + symbols indicates symptom severity, with ++++ as maximum level. 
Transcript profiling of defense-related genes in $B$. distachyon ABR6 and Bd21. To investigate the role of phytohormonedependent defense responses in Brachypodium spp. upon P. coronata f. sp. avenae infection, the temporal expression profile of several defense-related genes involved in salicylic acid (SA), ethylene (ET), and jasmonic acid (JA) signaling pathways, as well as genes involved in callose synthesis and the phenylpropanoid pathway, were examined. This analysis was undertaken for ABR6 and Bd21 during the early stages of infection (up to $3 \mathrm{dpi}$ ), when there were not significant differences in fungal growth among isolates in both

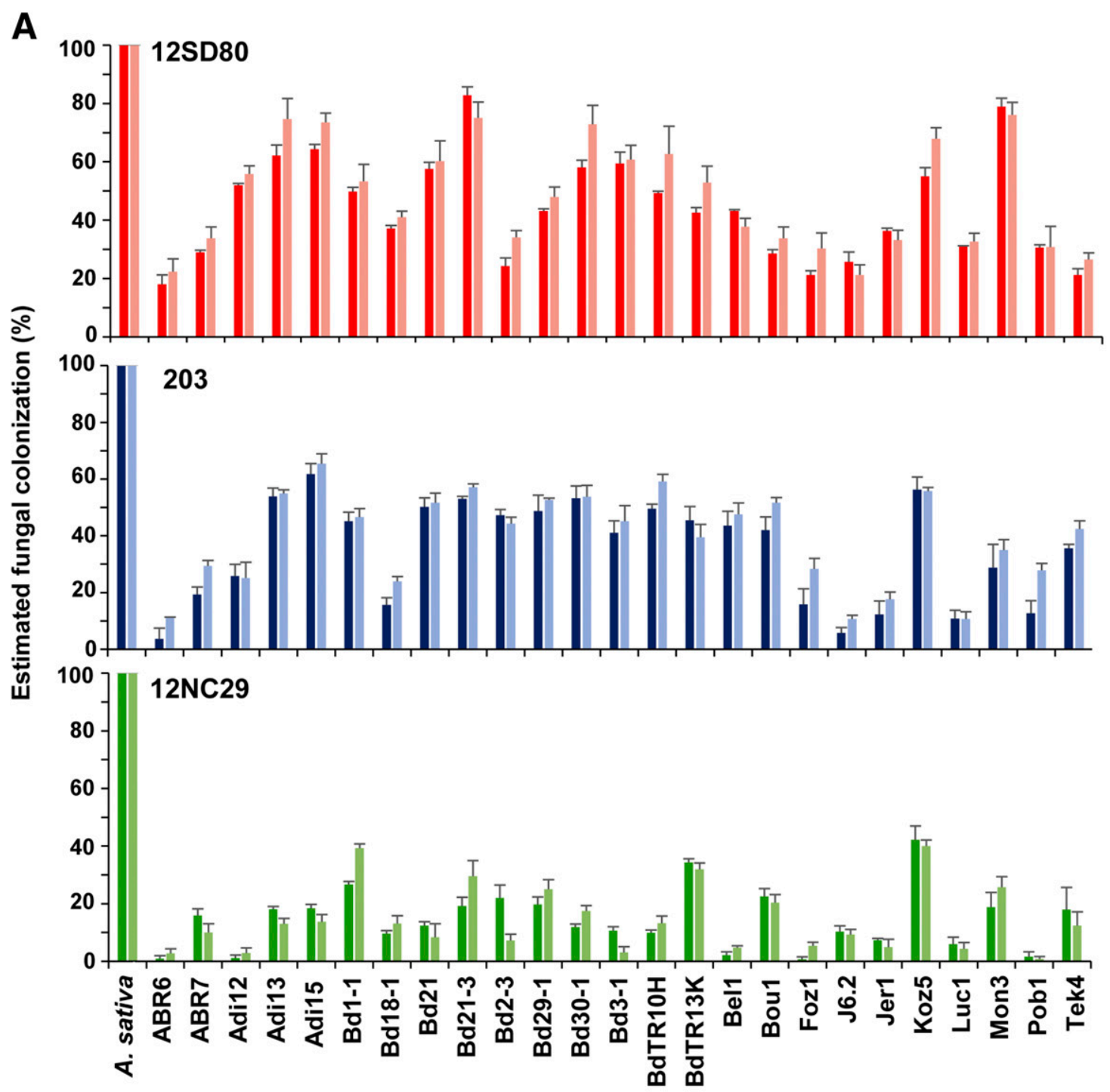

B
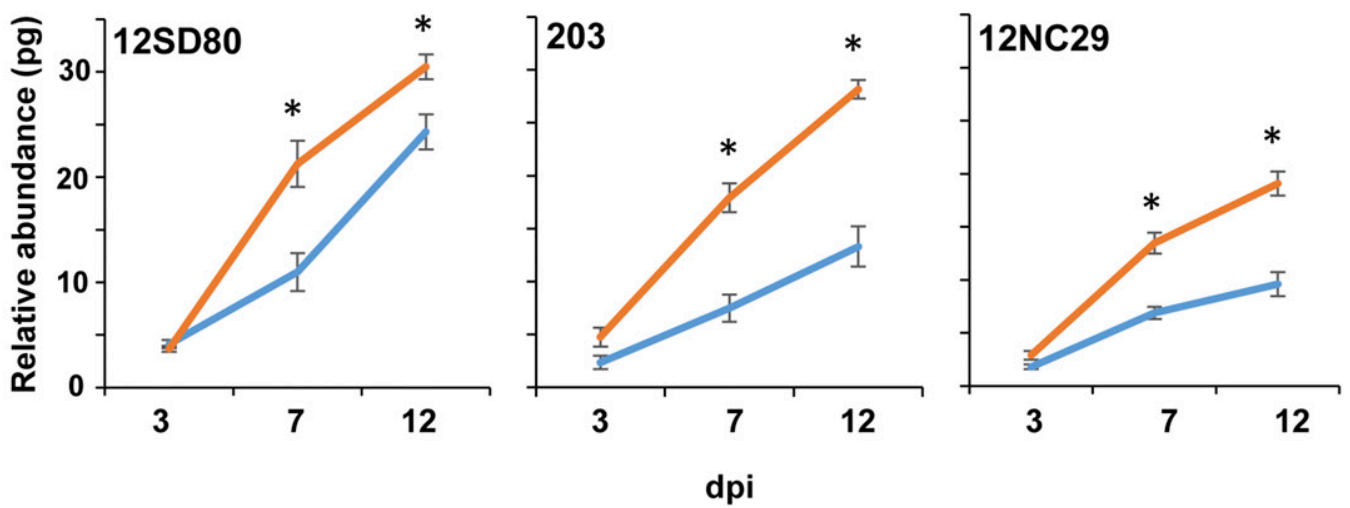

Fig. 2. Colonization of Brachypodium accessions by Puccinia coronata f. sp. avenae. A, Fungal growth estimates in foliar tissue for isolates 12 SD80, 203, and $12 \mathrm{NC} 29$ depicted by the percentage of colonized area at 14 days postinfection (dpi). Crown rust susceptible oat (Avena sativa) variety Marvelous serves as positive experimental control. Results from two independent experiments for each isolate are shown with distinct color intensities and each bar represents a mean value in one independent experiment (biological replicate). Error bars represent standard error of mean of three leaves (technical replicates) within one independent experiment. B, Quantification of fungal DNA for each rust isolate in B. distachyon accessions ABR6 (blue line) and Bd21 (orange line). Error bars represent standard error of mean of four independent experiments (biological replicates). Asterisks indicate statistically significant differences $(t$ test, $P \leq 0.05)$. 
accessions (Fig. 2B). Three possible references genes were evaluated for data normalization: GAPDH, Ubi4, and Ubil8 (Hong et al. 2008). qRT-PCR primers for the GAPDH gene showed the highest amplification efficiency $(98.4 \%)$ when compared with primers for Ubi4 (96\%) and Ubil8 (97.1\%) (Supplementary Fig. S4). The GAPDH gene was selected for data normalization because it displayed the least variation in expression (Cq values) when compared with Ubi4 and $U b i 18$ in mock- and fungus-infected tissues in both $B$. distachyon accessions and all time points together. GAPDH displayed steady expression in mock and infected tissues across time points in each

A
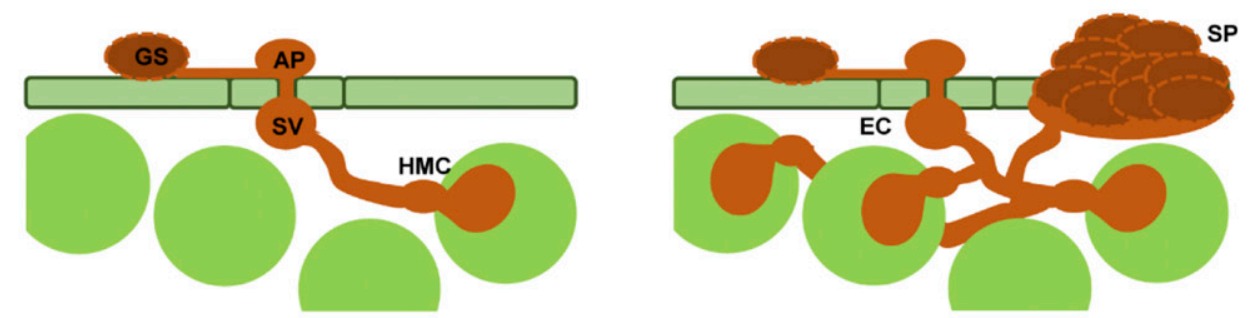

B

12 SD80

203

12 NC29

$\square \mathrm{GS} \backsim \mathrm{AP} \backsim \mathrm{SV} \square \mathrm{HMC} \backsim \mathrm{EC} \backsim \mathrm{SP}$

\section{ABR6}
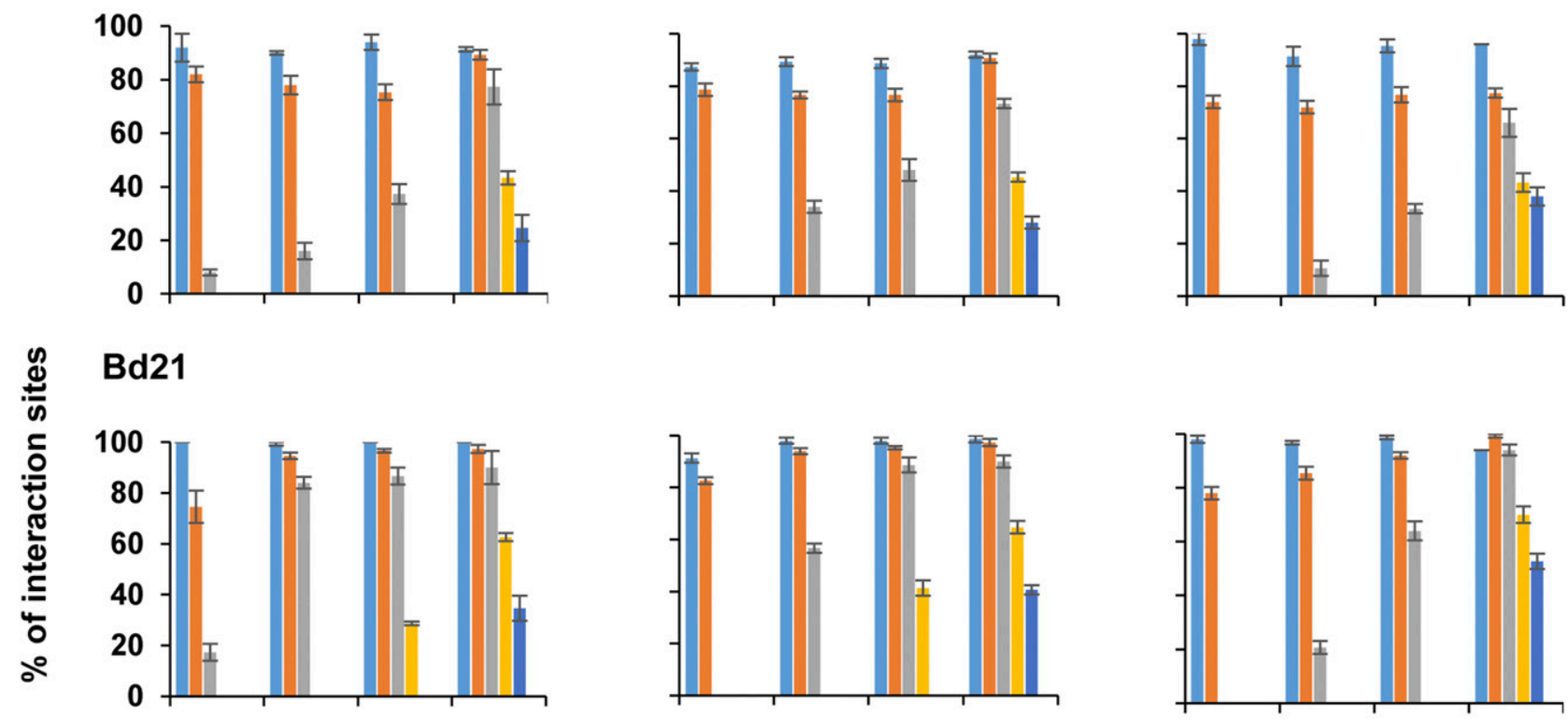

\section{Oat}
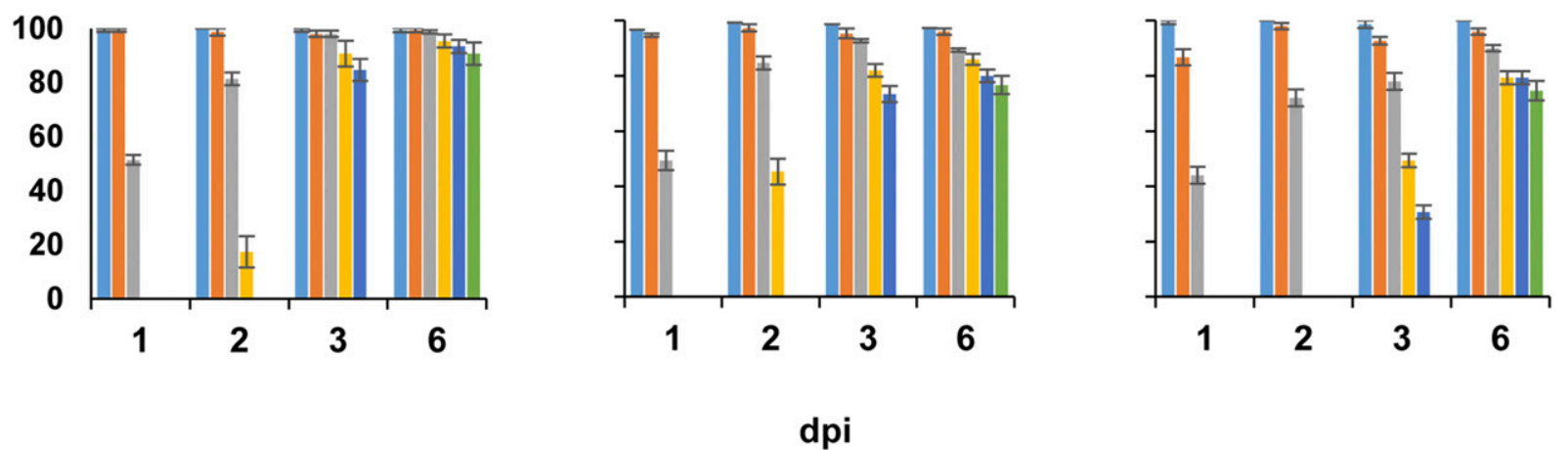

Fig. 3. Fungal development of Puccinia coronata f. sp. avenae in Brachypodium accessions. A, Illustration of P. coronata f. sp. avenae development in the plant. Germinated urediniospores (GS) form a penetration structure appressorium (AP) over a stoma. The fungus enters the mesophyll cavity and differentiates a substomatal vesicle (SV) and infection hypha. The establishment of a rust colony (EC) begins with the formation of a feeding structure (haustorium) which requires differentiation of a haustorial mother cell (HMC) near the hyphal tip. To undergo HMC formation, the rust fungus must come in contact with a mesophyll cell. B, Bars show the percentage of interaction sites with GS (light blue), formation of AP (orange), SV (gray), haustorium-mother cell (HMC, yellow), established colony (EC, dark blue), and EC with sporulation (SP, green) in a sample of 100 infection sites per independent experiment (biological replicate); dpi = days postinfection. Error bars represent standard error of mean of three independent biological replicates. 
accession, which further supported the suitability of this gene for data normalization. In general, expression of genes involved in the SA and ET signaling pathways were induced in ABR6 and $\mathrm{Bd} 21$ during the first $48 \mathrm{hpi}$; however, expression of JA biosynthesis genes was not altered (Fig. 4; Supplementary Fig. S5). Changes in gene expression were greater in ABR6 than Bd21 upon infection with isolates 12SD80 and 203 but the inverse was observed for isolate $12 \mathrm{NC} 29$. These findings suggest differences between ABR6 and $\mathrm{Bd} 21$ in the early signaling responses to $P$. coronata $\mathrm{f}$. sp. avenae infection.

Among the SA signaling pathway genes, expression of aberrant growth defects 2 (AGD2) peaked at 24 to 48 hpi with isolates 12SD80, 203, and 12NC29. The highest upregulation of AGD2 was observed in the interaction of 12SD80 and ABR6. Expression of alternative oxidase (AOX1A) was induced in ABR6 as early as 12 hpi with isolates 12 SD80 and 203 but it was not affected in response to isolate $12 \mathrm{NC} 29$. In contrast, $A O X 1 A$ was upregulated in $\mathrm{Bd} 21$ only at $48 \mathrm{hpi}$ in response to isolates $12 \mathrm{SD} 80$ and $12 \mathrm{NC} 29$. The pathogenesis-related $(P R)$ genes $P R I$ and $P R 5$ showed the greatest induction among all genes tested in response to all three crown rust isolates. The expression of both genes peaked at $48 \mathrm{hpi}$, except for PR5 expression after inoculation with 12NC29, which peaked at 24 hpi. Overall, induction of these SA-responsive genes occurred in all interactions but were remarkably stronger in ABR6 when inoculated with 12SD80 and 203, whereas Bd21 showed similar responses to all three isolates.

Expression of ETresponse factor 1 (ERF1) was maximal at $24 \mathrm{hpi}$ with all three isolates and, as observed for SA-responsive genes, expression of ERF1 was particularly high in ABR6 in response to isolates 12SD80 and 203. However, expression of an ET biosynthesis gene, aminocyclopropane-1-carboxylic acid oxidase (ACO1); two JA biosynthesis genes, lipoxygenase 2 (LOX2), and 12-oxophytodienoate reductase 3 (OPR3); WRKY18 transcription factor; and callose synthase did not change in either of the accessions in response to challenge with any of the three isolates. Expression of phenylalanine ammonia-lyase (PAL) was only slightly induced in ABR6 at 12 hpi with isolate 12SD80. Cinnamyl alcohol dehydrogenase (CAD) reached maximum induction in both accessions at 24 to 48 hpi with isolates 12 SD80 and 203. In response to infection with isolate $12 \mathrm{NC} 29$, this gene was only upregulated in $\mathrm{Bd} 21$ between 24 and 48 hpi.

Transcript profiling of BdSTP13 in B. distachyon ABR6 and Bd21. The expression of the Brachypodium ortholog of Lr67 (STP13) (Bradi1g69710) (Moore et al. 2015) was examined in

TABLE 2. Histological analysis of $\mathrm{H}_{2} \mathrm{O}_{2}$ accumulation in Brachypodium distachyon accessions ABR6 and $\mathrm{Bd} 21$ and oat lines that contain the Pc91 and Pcl4 genes in response to Puccinia coronata f. sp. avenae infection ${ }^{\mathrm{a}}$

\begin{tabular}{lccc}
\hline Isolates, plants & 2 dpi & 4 dpi & 6 dpi \\
\hline 12SD80 & & & \\
ABR6 & $10.7 \pm 1.8$ & $8.7 \pm 2$ & $4.3 \pm 1.2$ \\
Bd21 & $4 \pm 1.5$ & $3.3 \pm 0.9$ & $3.7 \pm 1.5$ \\
* Susceptible oat (Marvelous) & 0 & 0 & 0 \\
203 & & & \\
ABR6 & 0 & $0.3 \pm 0.3$ & $1.7 \pm 0.3$ \\
Bd21 & 0 & 0 & $2 \pm 0.6$ \\
* Susceptible oat (Marvelous) & 0 & 0 & 0 \\
12NC29 & 0 & & \\
ABR6 & $0.3 \pm 0.3$ & 0 & $1 \pm 0.6$ \\
Bd21 & 0 & 0 & 0 \\
* Susceptible oat (Marvelous) & & & \\
12SD80 & $61.3 \pm 7.5$ & $65 \pm 4.9$ & $47.7 \pm 4.1$ \\
** Oat (Pc91) & $1 \pm 0.6$ & $0.3 \pm 0.3$ & $0.7 \pm 0.7$ \\
* Oat (Pc14) & & & \\
12NC29 & $56 \pm 9.5$ & $54 \pm 6.4$ & $49 \pm 5.9$ \\
* Oat (Pc91) & 0 & $0.7 \pm 0.3$ & $0.7 \pm 0.3$ \\
* Oat (Pc14) &
\end{tabular}

\footnotetext{
a Values are calculated as means of three independent experiments \pm standard error of the mean; dpi $=$ days postinfection. Asterisks $*$ and $* *$ indicate negative and positive experimental controls, respectively.
}

accessions ABR6 and Bd21 upon infection with all three rust isolates, because it acts as a putative hexose transporter. BdSTP13 was induced in both accessions in response to the tested rust isolates (Fig. 5). Gene induction peaked at 24 to $48 \mathrm{hpi}$, except in the interaction between ABR6 and 12NC29, which showed low BdSTP13 transcript accumulation.

\section{DISCUSSION}

The lack of effective $P$. coronata $\mathrm{f}$. sp. avenae resistance in oat coupled with rapid evolution of pathogen virulence necessitates a search for new sources of resistance to control oat crown rust disease. To explore the potential of using Brachypodium spp. as a germplasm resource for disease resistance against $P$. coronata $\mathrm{f}$. $\mathrm{sp}$. avenae, we have characterized the interaction between three $P$. coronata $\mathrm{f}$. sp. avenae isolates and a panel of Brachypodium accessions, including $B$. distachyon and $B$. hybridum. At the macroscopic level, variation in resistance phenotypes was observed, which has been previously reported for other rust interactions with $B$. distachyon. In these studies, $P$. striiformis, $P$. graminis, and $P$. triticina infection phenotypes varied from immunity to a range of symptoms that included pustule formation and sporulation (Ayliffe et al. 2013; Figueroa et al. 2013; Garvin 2011). However, similar to Brachypodium-P. emaculata (switchgrass rust) interactions (Gill et al. 2015), we did not observe $P$. coronata f. sp. avenae sporulation on any Brachypodium accession, which supports the status of $B$. distachyon and B. hybridum as nonhosts for this pathogen. Macroscopic infection symptoms were often associated with chlorosis or necrosis; however, it was visually difficult to confirm whether these symptoms were a consequence of $P$. coronata $\mathrm{f}$. sp. avenae infection. Microscopic analysis showed that $P$. coronata f. sp. avenae isolates 12SD80, 203, and 12NC29 overcame prehaustorial resistance defenses and were able to colonize leaves of all Brachypodium accessions tested. These results are similar to the interactions observed between $P$. graminis f. sp. tritici and B. distachyon (Ayliffe et al. 2013). In light of these observations, we would like to emphasize that our definition of $B$. distachyon and $B$. hybridum as nonhosts is based on previous established terminology, which uses absence of sporulation as an indicator of resistance. However, given that both species tolerate growth of $P$. coronata f. sp. avenae, both B. distachyon and B. hybridum could be considered as nonnative hosts, and previous observations also reflect variations in susceptibility. Furthermore, changes in growth conditions may favor sporulation of $P$. coronata $\mathrm{f}$. sp. avenae in both B. distachyon and B. hybridum.

To better understand the phenotypic variation existing between $P$. coronata f. sp. avenae and Brachypodium interactions, we compared the extent of fungal growth on a range of accessions. The rust isolates included in this study represent three distinct physiological races (genotypes). A wide range of pathogen growth was observed on different Brachypodium accessions and was dependent on both plant and fungal genotypes. Some Brachypodium accessions tolerated more fungal growth when infected with isolates 12SD80 and 203 versus 12NC29 (i.e., Bd30-1, Bd3-1, and BdTR10H) (Fig. 2). Interestingly, we also identified accessions (i.e., Tek4) that tolerated more growth of isolates 12SD80 and $12 \mathrm{NC} 29$ than 203. These findings could be explained either by the lack of a plant target for pathogen effectors to promote infection effectively or the presence of race-specific components to resistance. The latter scenario implies that resistance is likely governed by variation in effector repertoires of the rust isolates and resistance $(R)$ genes present in the Brachypodium accessions. Given the close evolutionary relationship between oat and Brachypodium spp., it is possible that the accessions included in our study carry $R$ genes that can detect effectors of $P$. coronata f. sp. avenae. Isolates $12 \mathrm{SD} 80$ and $12 \mathrm{NC} 29$ display different virulence profiles on the oat differential set and the recent sequencing of these isolates provides evidence of extensive differences in effector gene 
complements of 12SD80 and 12NC29 (Miller et al. 2018). Future studies identifying and comparing the effector repertoires of rust species, including those in our study and others that infect Brachypodium (i.e., P. brachypodii), may help to explain our findings.
The precise contribution of ETI to nonhost rust resistance in Brachypodium remains elusive. Future efforts to dissect the genetic factors controlling resistance to $P$. coronata $\mathrm{f}$. $\mathrm{sp}$. avenae in $B$. distachyon will help to evaluate the model proposed by SchulzeLefert and Panstruga (2011), in which ETI is the major contributor
12SD80
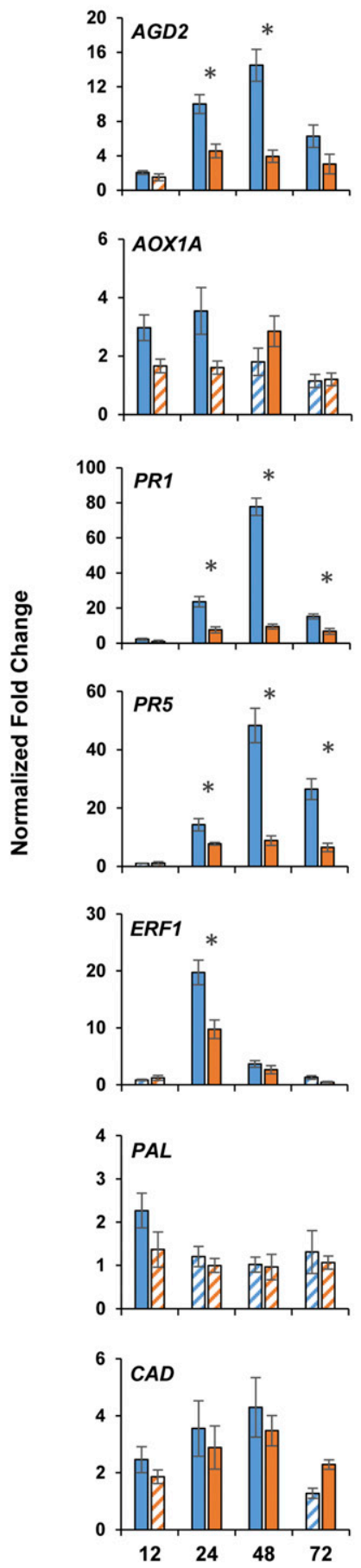

203
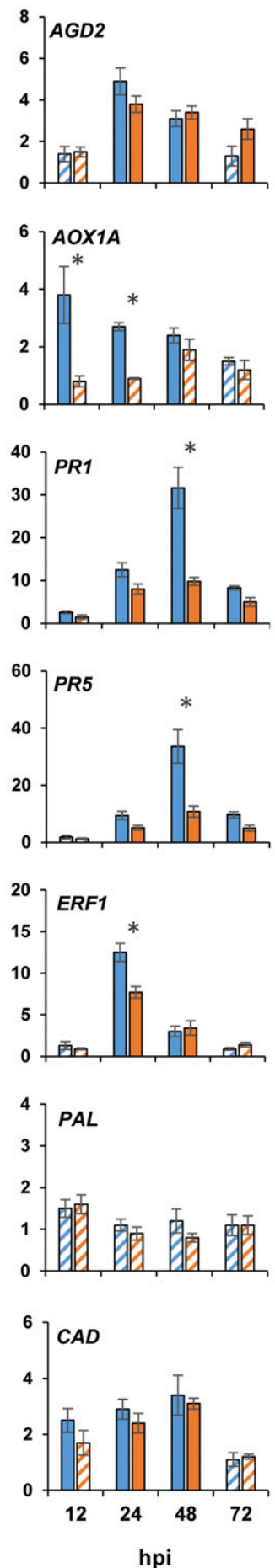

ABR6

$\square$ Bd21

12 NC29
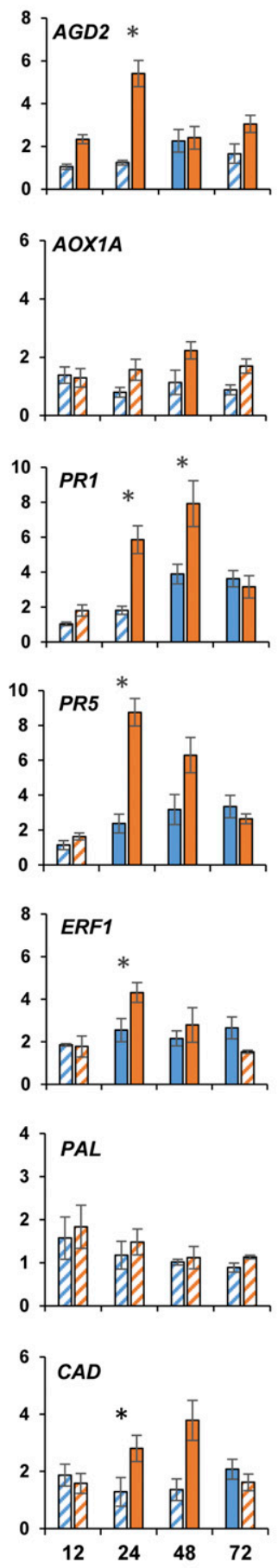

Fig. 4. Expression profiling of various defense-related genes in Brachypodium accessions in response to Puccinia coronata f. sp. avenae. Gene expression (foldchange) relative to mock inoculations in rust infected ABR6 (blue) and Bd21 (orange) plants of aberrant growth defects 2 (AGD2), alternative oxidase (AOX1A), pathogenesis-related $(P R)$ genes, ethylene response factor 1 (ERF1), phenylalanine ammonia-lyase (PAL), and cinnamyl alcohol dehydrogenase (CAD). Bar plots represent mean values of fold change per time point; hpi $=$ hours postinfection. Solid colored bars indicate a fold change value $\geq 2$ whereas hatched bars indicate values below this threshold. Error bars represent standard error of mean of three independent experiments (biological replicates). Asterisks indicate statistically significant differences $(P \leq 0.05)$ between ABR6 and Bd21 accessions as determined by a $t$ test. 
to NHR in plant species that are closely related to the natural host. Heterologous expression of fungal and bacterial effectors in several nonhost pathosystems supports that effector recognition by immunoreceptors contributes to resistance (Adlung et al. 2016; Giesbers et al. 2017; Lee et al. 2014; Stassen et al. 2013; Sumit et al. 2012) although, in some cases, effector recognition can occur in the absence of resistance (Giesbers et al. 2017; Goritschnig et al. 2012). Close examination of Brachypodium interactions with $P$. graminis ff. spp. tritici, avena, and phalaridis; P. triticina; and P. striiformis suggests that HR-induced cell death is rare (Ayliffe et al. 2013). However, the lack of HR in these interactions does not necessarily undermine the contribution of ETI to NHR, because there are instances when $R$-gene-mediated ETI (e.g., wheat stem rust resistance gene $\mathrm{Sr} 33$ ) can result in resistance without cell death (Periyannan et al. 2013). Further studies are needed to better understand the extent of ETI and HR contributions in NHR, given that molecular and genetic factors in these interactions could be pathosystem specific.

To investigate the role of reactive oxygen species (ROS) in $B$. distachyon response to $P$. coronata $\mathrm{f}$. sp. avenae, we examined accumulation of ROS in accessions ABR6 and Bd21, which display contrasting infection phenotypes. We found a small number of urediniospores from 12SD80 associated with ROS accumulation, while detection of ROS was rare for two other isolates. However, in these cases, the accumulation of ROS in ABR6 and Bd21 was substantially less than that detected in a resistant oat line carrying the resistance gene $P c 91$ (Table 2). These findings make the involvement of this ROS unlikely in the resistance of Brachypodium to P. coronata f. sp. avenae. In contrast to $\mathrm{H}_{2} \mathrm{O}_{2}$, phytohormones may play a thus-far-undefined role in modulating NHR in Brachypodium to rust pathogens.

Plant responses to pathogens are partly regulated through a complex interplay between SA, ET, and JA signaling pathways (Denancé et al. 2013). Gill et al. (2015) found that several defenserelated genes involved in SA, ET, and JA signaling pathways were induced in Brachypodium accessions infected with $P$. emaculata. In our study, upregulation of several SA-responsive genes and the key ET response regulator $E R F 1$ was detected, suggesting that SA and ET signaling pathways may positively regulate NHR against $P$. coronata f. sp. avenae. The $P R$ genes $P R 1$ and $P R 5$ were upregulated in response to all rust isolates and, given that $P R 1$ is a key marker gene of SA signaling (Kouzai et al. 2016; Sels et al. 2008), this further supports the idea that the activation of SA-dependent defense responses may contribute to the phenotypes observed in $B$. distachyon and $B$. hybridum during $P$. coronata $\mathrm{f}$. $\mathrm{sp}$. avenae infection. JA biosynthesis genes were not induced, making this hormone unlikely to play an active role in this NHR response. In contrast, ERF1, which acts as a key regulatory element in the ET/ JA-dependent defense responses, was upregulated, suggesting that ET-responsive genes may enhance NHR (Berrocal-Lobo et al. 2002; Lorenzo et al. 2003; Müller and Munné-Bosch 2015). PAL is a key enzyme in biosynthesis of polyphenolic compounds and lignin precursors and is often associated with host resistance responses against pathogens (Kalisz et al. 2015). Lignin deposition in response to pathogen attack is usually correlated with reinforcement of the cell wall and enhanced resistance (Miedes et al. 2014). Upregulation of $P A L$ does not appear to play a significant role in the responses of $B$. distachyon to $P$. coronata $\mathrm{f}$. sp. avenae; however, induction of $C A D$ may point to cell wall alterations in response to isolates $12 \mathrm{SD} 80$ and 203. A genome-wide transcriptional analysis of the interaction of P. coronata f. sp. avenae with ABR6 and $\mathrm{Bd} 21$ will help to elucidate the involvement of some of these specific processes in NHR, including phytohormone regulation.

Extensive $P$. coronata f. sp. avenae growth in some Brachypodium accessions implies that the pathogen is capable of nutrient accession for a period of time and possibly able to target susceptibility factors conserved between Brachypodium and oat. Little is known about the mechanisms underlying rust susceptibility. Pathogens can alter sugar partitioning in the host to accommodate their growth (Lapin and Van den Ackerveken 2013) and, thus, sugar transporter proteins (STP) may be targeted by rust fungi to increase nutrient availability (Dodds and Lagudah 2016). The wheat STP13 hexose transporter is implicated in supporting rust pathogens because mutations in this gene leads to broad-spectrum resistance (Moore et al. 2015). We examined the expression of the ortholog of wheat STP13 in Brachypodium during infection by $P$. coronata f. sp. avenae. Interestingly, the highest levels of BdSTP13 expression were obtained in accession $\mathrm{Bd} 21$, which is subjected to more rust growth than ABR6, suggesting that the gene may indeed serve as a susceptibility factor. Our results are consistent with previous findings that show that expression of Lr67 and its homeologs in wheat peaks at 24 hpi upon infection with the leaf rust fungus, P. triticina. Gene expression analysis of Lr67 as well as other STP 13 genes in Arabidopsis and grapevine indicates that the gene is also

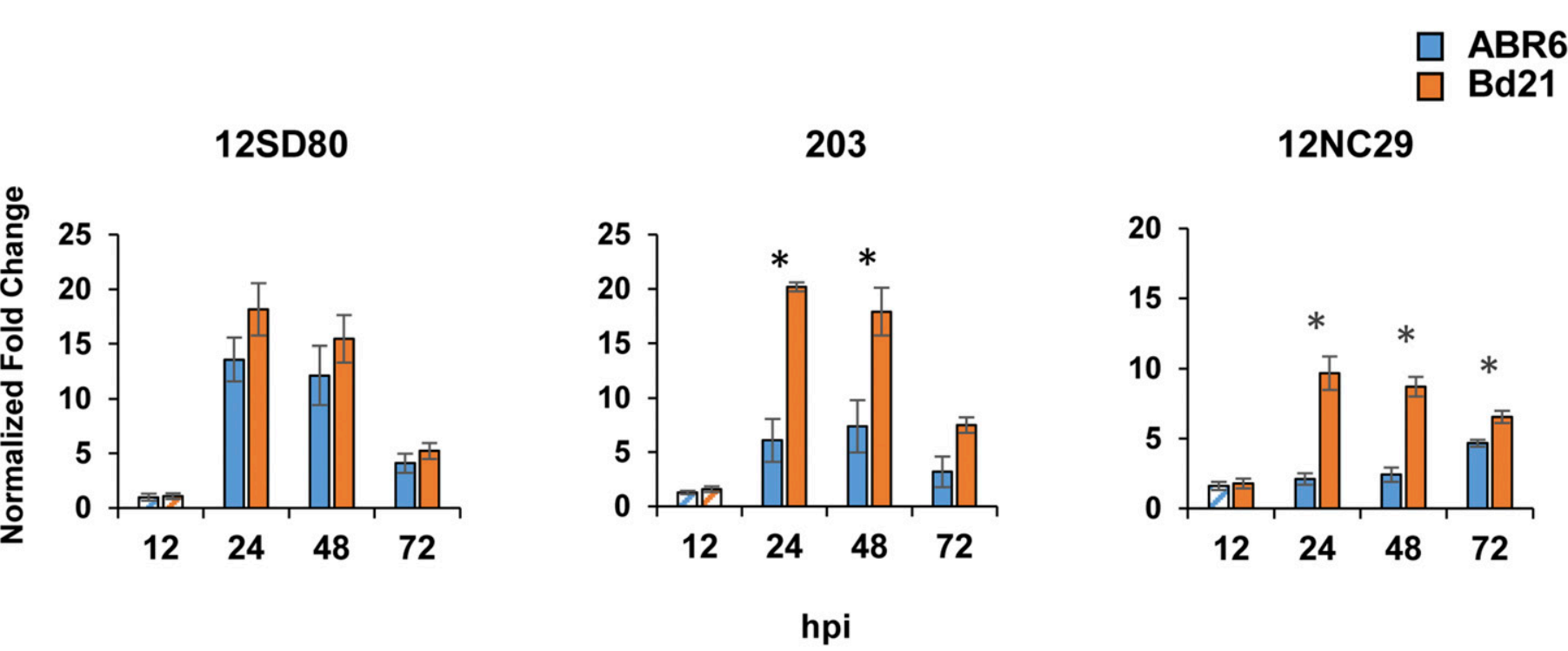

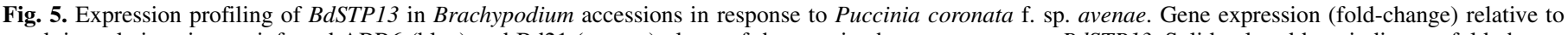

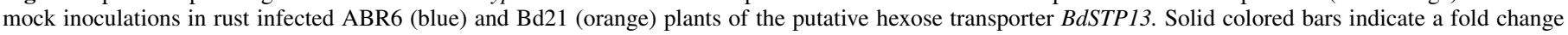

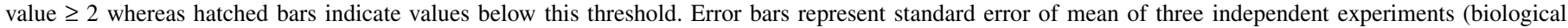

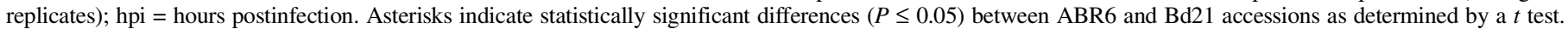


induced in response to pathogens (Hayes et al. 2010; Lemonnier et al. 2014; Moore et al. 2015). These observations provide a basis to study the contribution of sugar transport to rust susceptibility in an experimental system that is not as complex as in hexaploid oat and wheat.

Several studies have demonstrated the value of mining wild relatives of crop species to introduce disease resistance. Effective race-specific rust resistance has been introgressed into wheat (Triticum aestivum) from related species such as the $\mathrm{Sr} 50$ gene from rye (Secale cereale), which confers resistance to wheat stem rust by recognition of the corresponding AvrSr50 effector of $P$. graminis $\mathrm{f}$. sp. tritici (Chen et al. 2017; Mago et al. 2015). Similarly, functional transfer of the pigeonpea (Cajanus cajan) CcRppl resistance gene into soybean confers resistance against soybean rust (Phakopsora pachyrhizi), which demonstrates how heterologous resistance transgenes can be used for crop improvement (Kawashima et al. 2016). This interspecies transfer of disease resistance highlights the possibility that Brachypodium genes that confer NHR to Puccinia coronata f. sp. avenae could potentially be transferred to oat and provide disease resistance. As a next step, we are utilizing an ABR6 x Bd21 mapping population to identify resistance loci that could be tested in A. sativa. Both accumulation of fungal DNA and analysis of development of fungal infection structures (i.e., SV or HMC) can be used to phenotype the ABR6 $\times \mathrm{Bd} 21$ mapping population. In summary, our findings indicate that Brachypodium is a suitable species for evaluating NHR to $P$. coronata $\mathrm{f}$. sp. avenae and is a potential source of novel disease resistance for oat. The rapid expansion of genomic resources, including fully sequenced genomes and assessment of genetic diversity among Brachypodium genotypes (Gordon et al. 2014, 2017; The International Brachypodium Initiative 2010), enables this species to be exploited for engineering disease resistance in closely related crop species.

\section{ACKNOWLEDGMENTS}

We thank P. N. Dodds and E. Henningsen for discussions and comments during manuscript preparation, R. Caspers and L. van Lierop for technical support, and the University Imaging Centers (http://uic.umn.edu) and staff support at the University of Minnesota for using microscopy equipment.

\section{LITERATURE CITED}

Adlung, N., Prochaska, H., Thieme, S., Banik, A., Blüher, D., John, P. 2016. Non-host resistance induced by the Xanthomonas effector XopQ is widespread within the genus Nicotiana and functionally depends on EDS1. Front. Plant Sci. 7:1796.

Ayliffe, M., Singh, D., Park, R., Moscou, M. J., and Pryor, T. 2013. The infection of Brachypodium distachyon with selected grass rust pathogens. Mol. Plant-Microbe Interact. 26:946-957.

Barbieri, M., Marcel, T. C., and Niks, R. E. 2011. Host status of false brome grass to the leaf rust fungus Puccinia brachypodii and the stripe rust fungus P. striiformis. Plant Dis. 95:1339-1345.

Berrocal-Lobo, M., Molina, A., and Solano, R. 2002. Constitutive expression of ETHYLENE-RESPONSE-FACTOR1 in Arabidopsis confers resistance to several necrotrophic fungi. Plant J. 29:23-32.

Bettgenhaeuser, J., Corke, F. M. K., Opanowicz, M., Green, P., Hernández-Pinzón, I., and Doonan, J. H. 2017. Natural variation in Brachypodium links vernalization and flowering time loci as major flowering determinants. Plant Physiol. 173:256-268.

Bettgenhaeuser, J., Gilbert, B., Ayliffe, M., and Moscou, M. J. 2014. Nonhost resistance to rust pathogens-a continuation of continua. Front. Plant Sci. 5:664.

Bossolini, E., Wicker, T., Knobel, P. A., and Keller, B. 2007. Comparison of orthologous loci from small grass genomes Brachypodium and rice: Implications for wheat genomics and grass genome annotation. Plant J. 49: 704-717.

Cantu, D., Segovia, V., MacLean, D., Bayles, R., Chen, X., and Kamoun, S. 2013. Genome analyses of the wheat yellow (stripe) rust pathogen Puccinia striiformis f. sp. tritici reveal polymorphic and haustorial expressed secreted proteins as candidate effectors. BMC Genomics 14:270.

Carson, M. L. 2011. Virulence in oat crown rust (Puccinia coronata f. sp. avenae) in the United States from 2006 through 2009. Plant Dis. 95: 1528-1534.
Catanzariti, A. M., Dodds, P. N., Lawrence, G. J., Ayliffe, M. A., and Ellis, J. G. 2006. Haustorially expressed secreted proteins from flax rust are highly enriched for avirulence elicitors. Plant Cell 18:243-256.

Chang, T. D., and Sadanaga, K. 1964. Crosses of six monosomics in Avena sativa $\mathrm{L}$. with varieties, species, and chlorophyll mutants. Crop Sci. 4: 589-593.

Chen, J., Upadhyaya, N. M., Ortiz, D., Sperschneider, J., Li, F., and Bouton, C. 2017. Loss of AvrSr50 by somatic exchange in stem rust leads to virulence for $\mathrm{Sr} 50$ resistance in wheat. Science 358:1607-1610.

Chong, J., Leonard, K. J., and Salmeron, J. J. 2000. A North American system of nomenclature for Puccinia coronata f. sp. avenae. Plant Dis. 84:580-585.

Dawson, A. M., Bettgenhaeuser, J., Gardiner, M., Green, P., Hernández-Pinzón, I., and Hubbard, A. 2015. The development of quick, robust, quantitative phenotypic assays for describing the host-nonhost landscape to stripe rust. Front. Plant Sci. 6:876.

Denancé, N., Sánchez-Vallet, A., Goffner, D., and Molina, A. 2013. Disease resistance or growth: The role of plant hormones in balancing immune responses and fitness costs. Front. Plant Sci. 4:155.

Dodds, P. N., and Lagudah, E. S. 2016. Starving the enemy. Science 354: 1377-1378.

Dodds, P. N., and Rathjen, J. P. 2010. Plant immunity: Towards an integrated view of plant-pathogen interactions. Nat. Rev. Genet. 11:539-548.

Duplessis, S., Cuomo, C. A., Linc, Y. C., Aertsd, A., Tisseranta, E., and Veneault-Fourreya, C. 2011. Obligate biotrophy features unraveled by the genomic analysis of rust fungi. Proc. Natl. Acad. Sci. USA 108:9166-9171.

Ellis, J. G., Lagudah, E. S., Spielmeyer, W., and Dodds, P. N. 2014. The past, present and future of breeding rust resistant wheat. Front. Plant Sci. 5:641.

Figueroa, M., Alderman, S., Garvin, D. F., and Pfender, W. F. 2013. Infection of Brachypodium distachyon by formae speciales of Puccinia graminis: Early infection events and host-pathogen incompatibility. PLoS One 8: e56857.

Figueroa, M., Castell-Miller, C. V., Li, F., Hulbert, S. H., and Bradeen, J. M. 2015. Pushing the boundaries of resistance: Insights from Brachypodiumrust interactions. Front. Plant Sci. 6:558.

Flor, H. 1971. Current status of the gene-for-gene concept. Annu. Rev. Phytopathol. 9:275-296.

Garnica, D. P., Nemri, A., Upadhyaya, N. M., Rathjen, J. P., and Dodds, P. N. 2014. The ins and outs of rust haustoria. PLoS Pathog 10:e1004329.

Garvin, D. F. 2011. Investigating rust resistance with the model grass $\mathrm{Bra}$ chypodium. Pages 89-91 in: Proc. 2011 Borlaug Global Rust Initiative Tech. Workshop, St. Paul, MN. R. McIntosh, ed.

Garvin, D. F., Gu, Y. Q., Hasterok, R., Hazen, S. P., Jenkins, G., and Mockler, T. C. 2008. Development of genetic and genomic research resources for Brachypodium distachyon, a new model system for grass crop research. Crop Sci. 48:S69-S84.

Giesbers, A. K. J., Pelgrom, A. J. E., Visser, R. G. F., Niks, R. E., Van den Ackerveken, G., and Jeuken, M. J. W. 2017. Effector-mediated discovery of a novel resistance gene against Bremia lactucae in a nonhost lettuce species. New Phytol. 216:915-926.

Gill, U. S., Uppalapati, S. R., Nakashima, J., and Mysore, K. S. 2015. Characterization of Brachypodium distachyon as a nonhost model against switchgrass rust pathogen Puccinia emaculata. BMC Plant Biol. 15:113.

Gordon, S. P., Contreras-Moreira, B., Woods, D. P., Des Marais, D. L., Burgess, D., and Shu, S. 2017. Extensive gene content variation in the Brachypodium distachyon pan-genome correlates with population structure. Nat. Commun. 8: Article 2184

Gordon, S. P., Priest, H., Des Marais, D. L., Schackwitz, W., Figueroa, M., and Martin, J. 2014. Genome diversity in Brachypodium distachyon: Deep sequencing of highly diverse inbred lines. Plant J. 79:361-374.

Goritschnig, S., Krasileva, K. V., Dahlbeck, D., and Staskawicz, B. J. 2012. Computational prediction and molecular characterization of an oomycete effector and the cognate Arabidopsis resistance gene. PLoS Genet. 8: e1002502.

Hacquard, S., Joly, D. L., Lin, Y. C., Tisserant, E., Feau, N., and Delaruelle, C. 2012. A comprehensive analysis of genes encoding small secreted proteins identifies candidate effectors in Melampsora larici-populina (poplar leaf rust). Mol. Plant-Microbe Interact. 25:279-293.

Hayes, M. A., Feechan, A., and Dry, I. B. 2010. Involvement of abscisic acid in the coordinated regulation of a stress-inducible hexose transporter (VvHT5) and a cell wall invertase in grapevine in response to biotrophic fungal infection. Plant Physiol. 153:211-221.

Heath, M. C. 2000. Nonhost resistance and nonspecific plant defenses. Curr. Opin. Plant Biol. 3:315-319.

Holland, J. B., and Munkvold, G. P. 2001. Genetic relationships of crown rust resistance, grain yield, test weight, and seed weight in oat. Crop Sci. 41: 1041-1050.

Hong, S. Y., Seo, P. J., Yang, M. S., Xiang, F., and Park, C. M. 2008. Exploring valid reference genes for gene expression studies in Brachypodium distachyon by real-time PCR. BMC Plant Biol. 8:112. 
Kalisz, S., Oszmiański, J., and Wojdylo, A. 2015. Increased content of phenolic compounds in pear leaves after infection by the pear rust pathogen. Physiol. Mol. Plant Pathol. 91:113-119.

Kawashima, C. G., Guimaraes, G. A., Nogueira, S. R., MacLean, D., Cook, D. R., and Steuernagel, B. 2016. A pigeonpea gene confers resistance to Asian soybean rust in soybean. Nat. Biotechnol. 34:661-665.

Kouzai, Y., Kimura, M., Yamanaka, Y., Watanabe, M., Matsui, H., and Yamamoto, M. 2016. Expression profiling of marker genes responsive to the defense-associated phytohormones salicylic acid, jasmonic acid and ethylene in Brachypodium distachyon. BMC Plant Biol. 16:59.

Lapin, D., and Van den Ackerveken, G. 2013. Susceptibility to plant disease: More than a failure of host immunity. Trends Plant Sci. 18:546-554.

Lee, H. A., Kim, S. Y., Oh, S. K., Yeom, S. I., Kim, S. B., and Kim, M. S. 2014. Multiple recognition of RXLR effectors is associated with nonhost resistance of pepper against Phytophthora infestans. New Phytol. 203: 926-938.

Lemonnier, P., Gaillard, C., Veillet, F., Verbeke, J., Lemoine, R., and Coutos-Thévenot, P. 2014. Expression of Arabidopsis sugar transport protein STP13 differentially affects glucose transport activity and basal resistance to Botrytis cinerea. Plant Mol. Biol. 85:473-484.

Livak, K. J., and Schmittgen, T. D. 2001. Analysis of relative gene expression data using real-time quantitative PCR and the $2^{-\Delta \Delta C T}$ method. Methods 25: 402-408.

López-Alvarez, D., López-Herranz, M. L., Betekhtin, A., and Catalán, P. 2012. A DNA barcoding method to discriminate between the model plant Brachypodium distachyon and its close relatives $B$. stacei and B. hybridum (Poaceae). PLoS One 7:e51058

Lorenzo, O., Piqueras, R., Sánchez-Serrano, J. J., and Solano, R. 2003. ETHYLENE RESPONSE FACTOR1 Integrates Signals from Ethylene and Jasmonate Pathways in Plant Defense. Plant Cell 15:165-178.

Mago, R., Zhang, P., Vautrin, S., Šimková, H., Bansal, U., and Luo, M. C. 2015. The wheat Sr50 gene reveals rich diversity at a cereal disease resistance locus. Nat. Plants 1: Article 15186.

Maia, T., Badel, J. L., Marin-Ramirez, G., Rocha, C. M., Fernandes, M. B., and da Silva, J. C. F. 2017. The Hemileia vastatrix effector HvEC-016 suppresses bacterial blight symptoms in coffee genotypes with the SH1 rust resistance gene. New Phytol. 213:1315-1329.

Mandadi, K. K., and Scholthof, K. B. G. 2012. Characterization of a viral synergism in the monocot Brachypodium distachyon reveals distinctly altered host molecular processes associated with disease. Plant Physiol. 160: 1432-1452.

Miedes, E., Vanholme, R., Boerjan, W., and Molina, A. 2014. The role of the secondary cell wall in plant resistance to pathogens. Front. Plant Sci. 5: 358.

Miller, M. E., Zhang, Y., Omidvar, V., Sperschneider, J., Schwessinger, B., and Raley, C. 2018. De novo assembly and phasing of dikaryotic genomes from two isolates of Puccinia coronata f. sp. avenae, the causal agent of oat crown rust. MBio 9:e01650-e17.

Moore, J. W., Herrera-Foessel, S., Lan, C., Schnippenkoetter, W., Ayliffe, M., and Huerta-Espino, J. 2015. A recently evolved hexose transporter variant confers resistance to multiple pathogens in wheat. Nat. Genet. 47: 1494-1498.

Müller, M., and Munné-Bosch, S. 2015. Ethylene response factors: A key regulatory hub in hormone and stress signaling. Plant Physiol. 169:32-41.

Mur, L. A., Allainguillaume, J., Catalan, P., Hasterok, R., Jenkins, G., Lesniewska, K., Thomas, L., and Vogel, J. 2011. Exploiting the Brachypodium tool box in cereal and grass research. New Phytol. 191:334-347.

Mysore, K. S., and Ryu, C. M. 2004. Nonhost resistance: How much do we know? Trends Plant Sci. 9:97-104.
Nazareno, E. S., Li, F., Smith, M., Park, R. F., Kianian, S. F., and Figueroa, M. 2018. Puccinia coronata f. sp. avenae: A threat to global oat production. Mol. Plant Pathol. 19:1047-1060.

Nemri, A., Saunders, D. G. O., Anderson, C., Upadhyaya, N. M., Win, J., and Lawrence, G. J. 2014. The genome sequence and effector complement of the flax rust pathogen Melampsora lini. Front. Plant Sci. 5:98.

Nürnberger, T., and Lipka, V. 2005. Non-host resistance in plants: New insights into an old phenomenon. Mol. Plant Pathol. 6:335-345.

Panstruga, R., and Dodds, P. N. 2009. Terrific protein traffic: The mystery of effector protein delivery by filamentous plant pathogens. Science 324:748-750.

Periyannan, S., Milne, R. J., Figueroa, M., Lagudah, E. S., and Dodds, P. N. 2017. An overview of genetic rust resistance: From broad to specific mechanisms. PLoS Pathog 13:e1006380.

Periyannan, S., Moore, J., Ayliffe, M., Bansal, U., Wang, X., and Huang, L. 2013. The gene Sr33, an ortholog of barley Mla genes, encodes resistance to wheat stem rust race Ug99. Science 341:786-788.

Ravensdale, M., Nemri, A., Thrall, P. H., Ellis, J. G., and Dodds, P. N. 2011. Co-evolutionary interactions between host resistance and pathogen effector genes in flax rust disease. Mol. Plant Pathol. 12:93-102.

Rutter, W. B., Salcedo, A., Akhunova, A., He, F., Wang, S., and Liang, H. 2017. Divergent and convergent modes of interaction between wheat and Puccinia graminis f. sp. tritici isolates revealed by the comparative gene coexpression network and genome analyses. BMC Genomics 18:291.

Salcedo, A., Rutter, W., Wang, S., Akhunova, A., Bolus, S., and Chao, S. 2017. Variation in the AvrSr35 gene determines Sr35 resistance against wheat stem rust race $\mathrm{Ug} 99$. Science 358:1604-1606.

Schulze-Lefert, P., and Panstruga, R. 2011. A molecular evolutionary concept connecting nonhost resistance, pathogen host range, and pathogen speciation. Trends Plant Sci. 16:117-125.

Sels, J., Mathys, J., De Coninck, B. M. A., Cammue, B. P. A., and De Bolle, M. F. C. 2008. Plant pathogenesis-related (PR) proteins: A focus on PR peptides. Plant Physiol. Biochem. 46:941-950.

Simons, M. D. 1985. Crown rust. Pages 131-172 in: The Cereal Rusts, Vol. II. Disease, Distribution, Epidemiology and Control. A. P. Roelfs and W. R. Bushnell, eds. Academic Press, New York.

Stassen, J. H. M., den Boer, E., Vergeer, P. W. J., Andel, A., Ellendorff, U., and Pelgrom, K. 2013. Specific in planta recognition of two GKLR proteins of the downy mildew Bremia lactucae revealed in a large effector screen in lettuce. Mol. Plant-Microbe Interact. 26:1259-1270.

Sumit, R., Sahu, B. B., Xu, M., Sandhu, D., and Bhattacharyya, M. K. 2012. Arabidopsis nonhost resistance gene PSS1 confers immunity against an oomycete and a fungal pathogen but not a bacterial pathogen that cause diseases in soybean. BMC Plant Biol. 12:87.

The International Brachypodium Initiative. 2010. Genome sequencing and analysis of the model grass Brachypodium distachyon. Nature 463:763-768.

Thordal-Christensen, H. 2003. Fresh insights into processes of nonhost resistance. Curr. Opin. Plant Biol. 6:351-357.

Thordal-Christensen, H., Zhang, Z., Wei, Y., and Collinge, D. B. 1997. Subcellular localization of $\mathrm{H}_{2} \mathrm{O}_{2}$ in plants. $\mathrm{H}_{2} \mathrm{O}_{2}$ accumulation in papillae and hypersensitive response during the barley-powdery mildew interaction. Plant J. 11:1187-1194.

Toruño, T. Y., Stergiopoulos, I., and Coaker, G. 2016. Plant-pathogen effectors: Cellular probes interfering with plant defenses in spatial and temporal manners. Annu. Rev. Phytopathol. 54:419-441.

Vogel, J. P., Tuna, M., Budak, H., Huo, N., Gu, Y. Q., and Steinwand, M. A. 2009. Development of SSR markers and analysis of diversity in Turkish populations of Brachypodium distachyon. BMC Plant Biol. 9:88.

Zipfel, C. 2008. Pattern-recognition receptors in plant innate immunity. Curr. Opin. Immunol. 20:10-16. 